Research paper

\title{
Features of follicular dendritic cells in ovine pharyngeal tonsil: An in vivo and in vitro study in the context of scrapie pathogenesis
}

\author{
Vinciane Toppets ${ }^{\mathrm{a}, *}$, Valerie Defaweux ${ }^{\mathrm{b}}$, Joelle Piret $^{\mathrm{a}}$, Nathalie Kirschvink ${ }^{\mathrm{c}}$, \\ Luc Grobet $^{\mathrm{a}}$, Nadine Antoine ${ }^{\mathrm{a}}$ \\ a Department of Morphology and Pathology, Laboratory of Animal Histology and Embryology, Faculty of Veterinary Medicine, \\ University of Liege, Belgium \\ b Laboratory of Human Histology, Faculty of Medicine, University of Liege, Belgium \\ c Animal Physiology, Veterinary Department, Faculty of Sciences, University of Namur FUNDP, Belgium
}

\section{A R T I C L E I N F O}

\section{Article history:}

Received 23 July 2010

Received in revised form 24 January 2011

Accepted 31 January 2011

\section{Keywords:}

Sheep

Scrapie

Pharyngeal tonsil

Follicular dendritic cell

Anti-FDC antibodies

\begin{abstract}
A B S T R A C T
Although the alimentary tract has been suggested as the most likely portal of entry in natural scrapie, a growing amount of data indicates that the respiratory system and more specifically the pharyngeal tonsils serve as a natural portal of entry for scrapie.

This study describes for the first time the broad cell populations in the lymphoid compartment of pharyngeal tonsils and more specifically inside the lymphoid follicles where the scrapie agent accumulates during the period of latency.

Follicular dendritic cells (FDCs), stromal cells located in the light zone of the germinal centre of lymphoid follicles, seem to be the principal causal factor in the accumulation of the infectious agent in transmissible spongiform encephalopathy (TSE) diseases. Knowing that efficient lymphoreticular prion propagation requires PrPc expression, we analysed the expression of PrPc with the mouse monoclonal antibody Pri 909 both in situ and on FDC-cluster-enriched cell suspensions.

In situ, a positive staining was observed in the germinal centre of pharyngeal lymph follicles. The germinal centre labelling was due to the presence of a follicular dendritic network as revealed after immunogold staining of isolated FDC clusters. Our results suggest that the pharyngeal lymphoreticular system and more specifically PrPc expressing follicular dendritic cells could serve as a prion "reservoir" during the latency phase, thus playing a key role during the scrapie lymphoinvasion.
\end{abstract}

(c) 2011 Elsevier B.V. All rights reserved.

\section{Introduction}

In humans and in many animal species, the tonsils are a part of the pharyngeal mucosal immune system (Ogra, 2000) and form a ring of lymphoid tissue in the pharyngeal wall, known as the Waldeyer's ring (Perry and Whyte, 1998).

\footnotetext{
* Corresponding author. Present address: Department of Morphology and Pathology, Laboratory of Animal Histology and Embryology, Faculty of Veterinary Medicine, University of Liege, Boulevard de Colonster, 20 Bat. B43a, 4000 Liege, Belgium. Tel.: +32 436640 85; fax: +3243664086 .

E-mail address: vtoppets@ulg.ac.be (V. Toppets).
}

In sheep, the palatine (tonsilla palatina), the lingual (tonsilla lingualis) and the tonsil of the soft palate (tonsilla veli palatini) are located in the oropharynx; the pharyngeal (tonsilla pharyngea) and tubal tonsils (tonsilla tubaria) in the nasopharynx, and the paraepiglottic tonsil (tonsilla paraepiglottica) in the laryngopharynx (Barone, 1997). Defined as tonsils with or without crypts based upon their relationship with the surface epithelium, they consist mainly of secondary lymph follicles separated by T-dependent zones, areas through which antigens can pass and where effector cells accumulate.

In sheep, the palatine and the pharyngeal tonsils contain the largest volume of lymphoid tissues and the greatest epithelial surface area of the oropharyngeal and the 
nasopharyngeal parts of the Waldeyer's ring, respectively (Casteleyn et al., 2007, 2008). Palatine tonsils are bilateral, are the size of a hazelnut and present one to three crypts covered by the buccal epidermoid epithelium (Gabriel and van den Broeck, 2003; Cocquyt et al., 2005). The non-cryptic pharyngeal tonsil is a unique and circumvoluated elevation located on the caudal part of the pharyngeal septum. The lymphoid compartment consists of secondary follicles lying underneath the pseudostratified columnar ciliary epithelium.

Massive intraepithelial lymphocyte infiltration suggests that these tonsils are perfectly adapted to sample foreign antigens.

Relatively easily accessible, palatine and pharyngeal tonsils thus appear to be of strong interest in the diagnosis of several diseases. It is well known that animal tonsils are the sites of entry and replication of several pathogens. Studies on the foot and mouth disease virus (FMDV) in sheep confirm that the tonsils are the main predilection sites for the persistence of this aphtovirus (Kitching and Hughes, 2002; Horsington and Zhang, 2007). High levels of PrPd have been detected in palatine tonsil follicles of sheep naturally infected with the scrapie agent (Jeffrey et al., 2001). Tonsillar biopsies can thus be useful in guaranteeing food safety (Thuring et al., 2002). Infection via the nasal route may also be possible in scrapie infected flocks. Recent experiments postulate that the upper respiratory tract, and more specifically the pharyngeal tonsil, serves as a natural portal of entry for the scrapie agent (Hamir et al., 2008). This hypothesis is sustained by the presence of microfold M cells in the ovine nasopharyngeal mucosal epithelium (Stanley et al., 2001; Casteleyn et al., 2010), since these cells have been shown to efficiently transcytose prion infectivity in an in vitro co-culture system (Heppner et al., 2001).

The mucosa-associated lymphoid tissues play an important role in scrapie pathogenesis. PrPd accumulates inside the germinal centres (McBride et al., 1992) before spreading to the sites of neuroinvasion. The cells implicated in prion pathogenesis are follicular dendritic cells (FDCs) which reside in the germinal centre (Jeffrey et al., 2000; Mabbott and Bruce, 2001). Numerous studies using chimaeric mice indicate that mature follicular dendritic cells are necessary for prion propagation within the lymphoreticular system (Brown et al., 1999). In the absence of mature FDCs, neuroinvasion following peripheral challenge is significantly impaired in scrapie pathogenesis (Mabbott et al., 2000; Montrasio et al., 2000). The ability to recognise ovine FDCs is limited. In fact, among the various anti-FDC antibodies commercially available, DRC1 (Naiem et al., 1983; Johnson et al., 1986), FDC-M1 (Kosco et al., 1992) and CNA.42 (Raymond et al., 1997; Lezmi et al., 2001) all fail to recognise specifically FDCs from all the secondary ruminants lymph organs. FDC-B1, a new mouse monoclonal antibody, has recently been produced and characterised by Melot et al. (2004). The antigen detected by FDC-B1 is expressed exclusively on the surface of FDCs in all ruminant lymphoid organs.

The aims of our study were (i) the identification of the FDCs inside the pharyngeal tonsil; (ii) the study of their morphological characteristics and (iii) the analysis, in vivo and in vitro, of the PrPc expression on their cell membrane.
This approach will be useful for future comparative studies on the implication of the FDC network in the replication of the scrapie agent in the nasopharyngeal mucosa of sheep with different polymorphisms in the host PrP gene.

\section{Materials and methods}

\subsection{Sample collection}

Pharyngeal and palatine tonsils were obtained at a local abattoir from clinically healthy sheep aged from 4 to 6 months. These animals showed the ARR/ARR genotype resistant toward scrapie.

\subsection{Immunohistochemistry}

Some specimens were immersed in Tissue-Tek OCT embedding medium (SAKURA, Zouterwoude, the Netherlands), snap-frozen and stored at $-20^{\circ} \mathrm{C}$ until processing for immunohistochemistry. Sections were cut at $-15^{\circ} \mathrm{C}$ with a microtome (MICRON HM 500 OM) and deposited on glass slides coated with poly-L-lysine (Sigma, St. Louis, USA), air-dried, fixed in acetone for $10 \mathrm{~min}$ at $4{ }^{\circ} \mathrm{C}$, and stored at $-80^{\circ} \mathrm{C}$ until use.

After rehydration, the cryosections were incubated for $1 \mathrm{~h}$ at room temperature with antibodies directed against the selected lymphoid cell populations or with those which react with ovine PrPc. Immune cells were stained with the following antibodies: follicular dendritic cells (FDCs) identified with two mouse monoclonal antibodies: FDC-B1 (undiluted hybridoma supernatant) kindly provided by Melot et al. (2004) and CNA.42 (1/100) (Dako, Glostrup, Denmark), B cells revealed with a mouse antihuman CD79 acy mAb (clone HM 57) (1/1000) (Dako, Glostrup, Denmark) and $T$ cells with a rabbit anti-CD3 polyclonal antibody (1/600) (Dako, Glostrup, Denmark). Cellular prion protein expression was analysed on tissue sections and on FDC clusters with a mouse anti-human monoclonal antibody Pri 909 (SPIbio, Montigny le Bretonneux, France) raised against an epitope located at amino acid sequence $214-230$ in the protein and diluted at $1 / 100$ in PBS. The samples were rinsed three times in the same buffer. They were then incubated with a conjugated goat anti-mouse (for FDC-B1, CNA.42, CD79 and anti-PrPc $m A b$ ) or goat anti-rabbit (for CD3) immunoglobulin peroxidase labelled polymer (Amplification EnVision ${ }^{\circledR}$ System-HRP, Dako, Glostrup, Denmark) for $30 \mathrm{~min}$ at room temperature. Peroxidase activity was revealed with 9ethyl-3-aminocarbazole (AEC, Zymed, San Francisco, USA) combined to $\mathrm{H}_{2} \mathrm{O}_{2}$ as substrate for $12 \mathrm{~min}$. The specificity of the antibodies was tested using an isotype control antibody and negative controls were obtained by omitting the primary antibody. The specimens were counterstained with Mayer's haematoxylin.

\subsection{Isolation of FDC clusters}

Three protocols were tested. The first two compared the efficiency of two enzymatic cocktails in terms of FDC cluster numbers and of PrPc expression by freshly isolated FDCs. Pharyngeal tonsils were cut into $1 \mathrm{~mm}$ thick slices. The 
lymphoid follicles were roughly isolated from the connective and epithelial tissues under a biomicroscope (SMZ-2B, Nikon, Japan) and submitted to two successive enzymatic digestions of $20 \mathrm{~min}$ at $37^{\circ} \mathrm{C}$, under agitation. The following enzymatic cocktails were tested:

Cocktail 1: Collagenase A (Boehringer-Mannheim, Germany) $2 \mathrm{mg} / \mathrm{ml}$ in $20 \mathrm{ml}$ of RPMI 1640 medium (Bio-Whittaker, Belgium) complemented with $1 \mathrm{mM}$ of ethylenediaminetetraacetic (EDTA) and 10\% foetal calf serum (FCS) (Perbio, Sweden).

Cocktail 2 (Tsunoda et al., 1990): Collagenase A (Boehringer-Mannheim, Germany) $1 \mathrm{mg} / \mathrm{ml}$; dispase (type II; Boehringer-Mannheim, Germany), $0.5 \mathrm{mg} / \mathrm{ml}$; DNase (type I; Boehringer-Mannheim, Germany), $0.04 \mathrm{mg} / \mathrm{ml}$ in $20 \mathrm{ml}$ of RPMI 1640 medium (BioWhittaker, Belgium) with $0.4 \%$ bovine serum albumin (BSA).

Whatever the cocktail used, after both stages of digestion, the supernatant was removed and centrifugated for $10 \mathrm{~min}$ at $200 \times \mathrm{g}$. The pellets were resuspended in PBS, pooled, filtrated on a nylon membrane with a pore size of $150 \mu \mathrm{m}$ (Sefar A.G., Heiden, Switzerland) and enriched in FDC clusters by two repetitive sedimentation gradients through FCS, at $4{ }^{\circ} \mathrm{C}$ for $20 \mathrm{~min}$. The higher part of the gradient was eliminated and the phase containing FDCs centrifugated again. The cell suspensions were processed to produce cytospecimens at $200 \times g$ for $1 \mathrm{~min}$ on glass slides (Shandon cytospin 4, Thermo, Runcorn, UK). They were then fixed in acetone for $10 \mathrm{~min}$ at $4{ }^{\circ} \mathrm{C}$, air dried and stored at $-80^{\circ} \mathrm{C}$ until use.

In the third protocol, after isolation performed with the second enzymatic cocktail, some FDC clusters were incubated for $15 \mathrm{~h}$ at $37^{\circ} \mathrm{C}$, with $5 \% \mathrm{CO}_{2}$ as cell suspension in a plastic culture dish with the following medium: RPMI 1640, 2 mM L-glutamine, $50 \mu \mathrm{M}$ 2-mercaptoethanol, $5 \%$ FCS, $100 \mathrm{U} / \mathrm{ml}$ penicillin and $100 \mu \mathrm{g} / \mathrm{ml}$ streptomycin (Invitrogen, California, USA). The non-adhering cells were collected after $6 \mathrm{~h}$, centrifugated $(200 \times \mathrm{g})$ and transferred to a new dish with fresh medium for an additional $9 \mathrm{~h}$ incubation. The cells were collected again, centrifugated, resuspended in PBS and processed to produce cytospecimens.

\subsection{Immunolocalisation of PrPc at electron microscopic level}

For ultrastuctural observations, pellets containing FDC clusters collected after $15 \mathrm{~h}$ of culture were incubated with Pri $909 \mathrm{mAb}$ diluted at $1 / 10$ in PBS, for $1 \mathrm{~h}$ at $4{ }^{\circ} \mathrm{C}$, washed with PBS, and then incubated with a goat anti-mouse antibody (dilution: 1/10 in PBS) conjugated with $10 \mathrm{~nm}$ gold particles (Aurion, the Netherlands) for $1 \mathrm{~h}$ on ice. The specificity of the antibodies was tested using an isotype control antibody and negative controls were obtained by omitting the primary antibody. After a wash in PBS, the cells were fixed for $2 \mathrm{~h}$ at $4{ }^{\circ} \mathrm{C}$ in a glutaraldehyde solution (2\%) in a $0.1 \mathrm{M}$ cacodylate buffer $(\mathrm{pH} 7.4)$ and then rinsed in the same buffer. The specimens were post-fixed for $30 \mathrm{~min}$ in a mixture of $1 \% \mathrm{OsO}_{4}$ and $1.5 \% \mathrm{~K}_{4} \mathrm{Fe}(\mathrm{CN})_{6}$ in a $0.1 \mathrm{M}$ cacodylate buffer ( $\mathrm{pH} 7.4$ ), dehydrated in a graded series of alcohols and embedded in EPON 812 (Fluka, Belgium). The resin specimen blocks were trimmed and ultra-thin sections of 70-90 nm of selected areas were cut, collected on copper 6200 grids and contrasted with uranyl acetate solution before examination with a ZEISS EM910 transmission electron microscope (Zeiss, Nanterre, France).

\section{Results}

\subsection{Morphology and immunohistochemistry of ovine pharyngeal tonsils}

The ovine pharyngeal tonsil was observed to be unpaired and was located in the caudal part of the pharyngeal septum. It had an approximate size of $3 \mathrm{~cm}$ in length and $1.5 \mathrm{~cm}$ in width.

Macroscopically, the outer surface was lined by a mucous membrane forming many longitudinal exophytic folds, rich in lymphoid structures. The central axis of the organ was occupied by a loose collagenous connective tissue rich in blood and lymphatic vessels and in adipose cells (Fig. 1).

Histologically, the luminal surface of the tonsil was covered by a deeply folded pseudostratified ciliary epithelium containing goblet mucous cells. In some locations, the epithelium was invaded by lymphoid cells, losing its typical structure providing a route to a reticular lymphoepithelium.

Numerous secondary lymphoid follicles surrounded by an interfollicular area formed the sub-epithelial lamina propria mucosae. Lymphoid follicles consisted of a germinal centre (GC) and a mantle zone (MZ) which generally faced the epithelium. CD79 positive B cells were located in

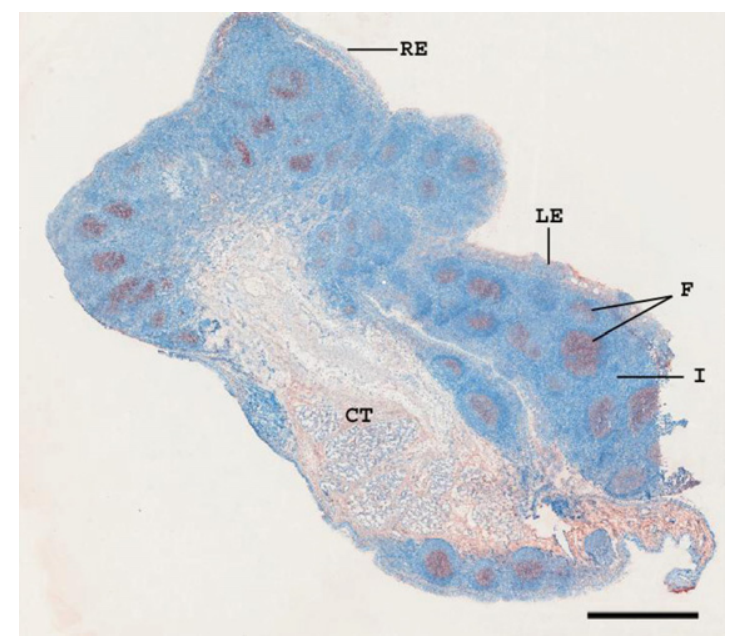

Fig. 1. Immunolabelling of ovine pharyngeal tonsillar cryosections with $\mathrm{mAb}$ : FDC-B1. Counterstaining with haematoxylin. The deeply folded mucous membrane is covered by a respiratory epithelium (RE) invaded in some locations by lymphoid cells providing a route to a reticular lymphoepithelium (LE). Inside the folds, 1 or 2 layers of secondary lymphoid follicles (F) are aligned side by side. The interfollicular area (I) is highly infiltrated by lymphoid cells. The central axis of the tonsil is filled with a loose collagenous connective tissue (CT) rich in blood and lymphatic vessels. Bar $=2 \mathrm{~mm}$. 

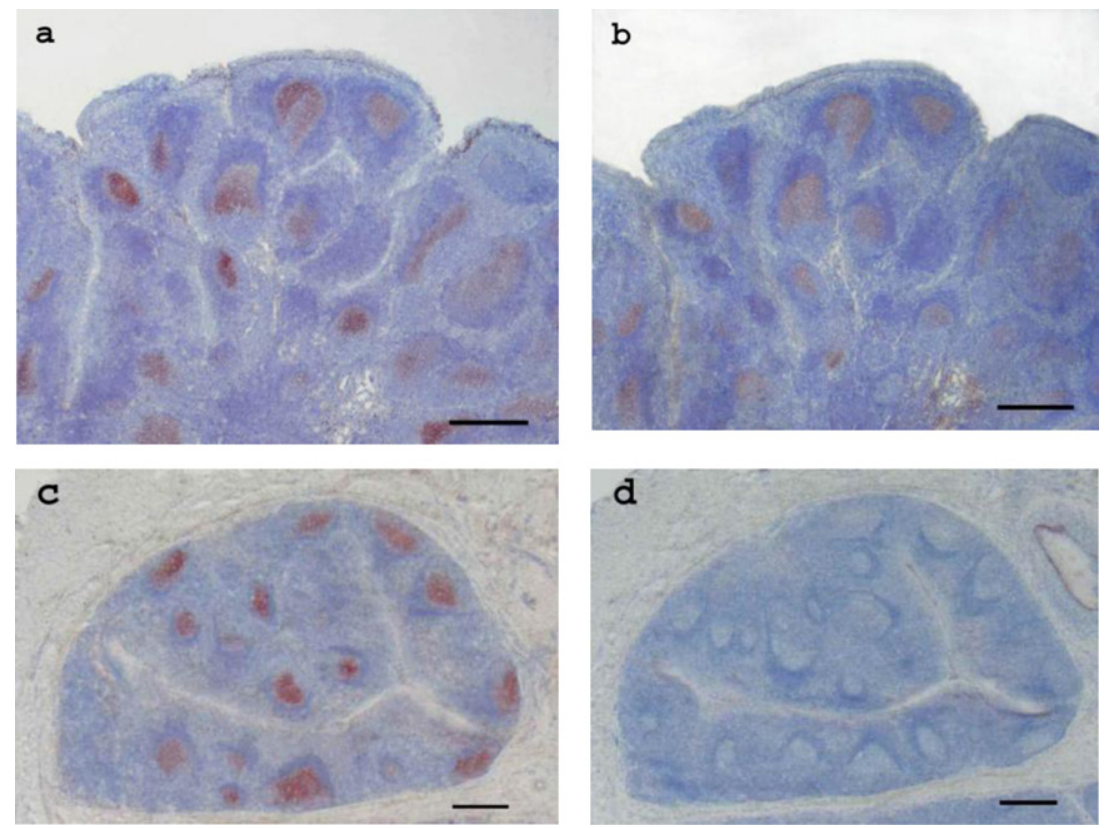

Fig. 2. Immunolabelling of ovine pharyngeal (a and b) and palatine (c and d) tonsillar cryosections with mAb: FBC-B1 (a and c) and CNA.42 (b and d). Counterstaining with haematoxylin. With FDC-B1 mAb, the germinal centres of the lymphoid follicles were stained in both the palatine and pharyngeal tonsils while CNA.42 mAb labelled the germinal centres of the pharyngeal tonsil only.

the GC and in the MZ of the lymphoid follicles. T lymphocytes were located mainly in the inter- and parafollicular area. Some sparse $\mathrm{CD} 3$ positive $\mathrm{T}$ cells were disseminated through the GC (data not shown).

Fig. 2 illustrates the FDC immunostaining obtained with FDC-B1 and CNA.42 antibodies tested on palatine and pharyngeal tonsils.

In the pharyngeal tonsils, an intense staining was observed with both antibodies in the light zone of the GC (Fig. 2a and b). At higher magnification, this zone clearly revealed a network-shaped distribution of the labelling. Some positive FDC extensions run through the dark zone and the mantle zone.

No significant labelling of the FDC network was obtained when using CNA.42 mAb in the palatine tonsils (Fig. $2 \mathrm{~d}$ ).

With the aim of revealing the PrPc expression by the FDC network, the Pri 909 mAb was tested on pharyngeal tonsil cryosections. A staining less intense in comparison with FDC-B1 labelling was revealed inside the germinal centres with the same distribution pattern. The mantle zone and the T cell area remained unstained (Figs. 3 and 4).

Moreover, PrPc was also located outside the lymphoid tissue. The respiratory epithelium and the connective tissues were lightly stained as verified by controls.

\subsection{Isolation of FDC clusters with preserved PrPC}

The FDC clusters prepared by enzymatic digestion appeared as round or ovoid aggregates of cells with an approximate size of $50 \mu \mathrm{m}$. The FDC membrane engulfed compacted lymphocytes and, following the orientation of the cluster, one or two FDC nuclei were distinct. Regarding the number of clusters after two sedimentation gradients, we obtained an average of 8 clusters $/ 5 \mu$ l cell suspension with the first enzymatic cocktail against an average of 46 clusters $/ 5 \mu l$ cell suspension with the second cocktail comparatively. After immunolabelling, the percentage and intensity of positive clusters also depended to some degree on the enzymatic cocktail used. The rare clusters obtained with cocktail 1 were slightly stained or were unlabelled by both FDC-B1 and Pri 909 mAb. Using cocktail 2, the FDC clusters were not immunostained by either FDC-B1 or by Pri $909 \mathrm{mAb}$.

The FDC clusters isolated with the second enzymatic cocktail were then submitted to an additional stage, lasting $15 \mathrm{~h}$, of culture in cell suspension conditions and this allowed the re-expression of PrPc at the cell surface of the FDCs.

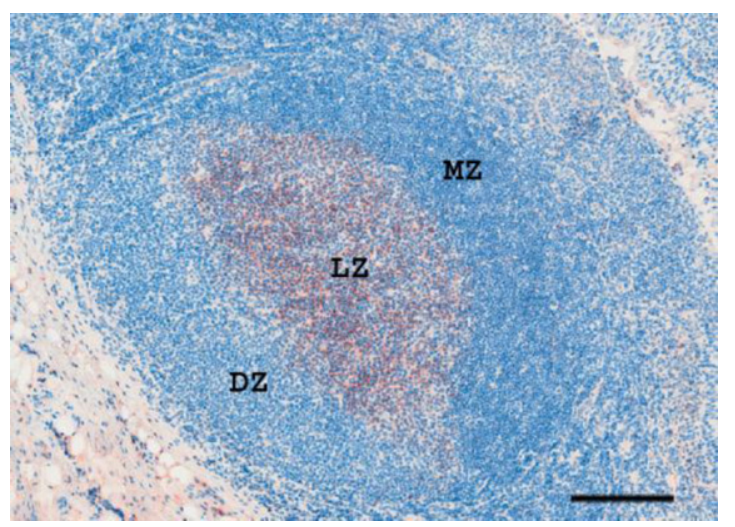

Fig. 3. Immunolabelling of pharyngeal tonsillar follicular dendritic cells with $\mathrm{mAb}$ : FBC-B1. Counterstaining with haematoxylin. The immunoreaction of the FDCs was limited to the light zone (LZ) of the germinal centre. Some labelled extensions were able to run through the dark zone (DZ) and the mantle zone $(\mathrm{MZ})$. Bar $=200 \mu \mathrm{m}$. 


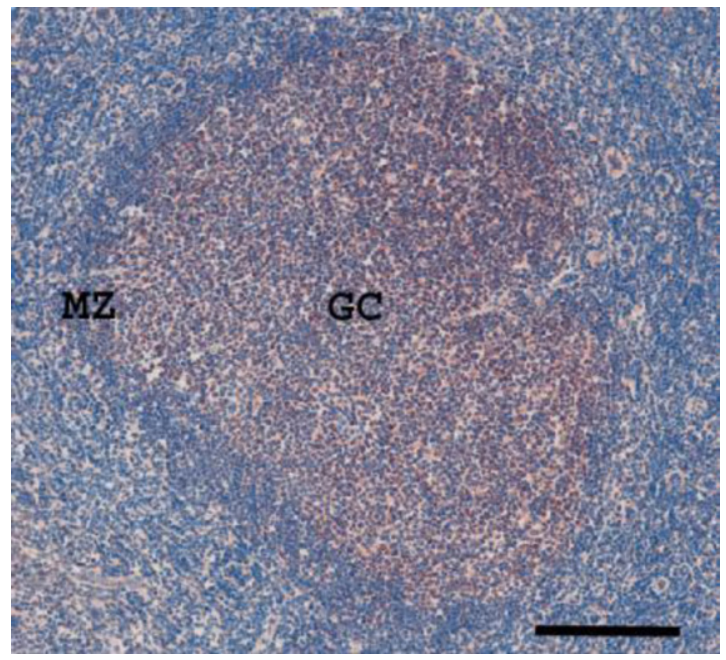

Fig. 4. Immunolabelling of a secondary lymphoid follicle with mAb: Pri 909. Counterstaining with haematoxylin. Pri $909 \mathrm{mAb}$ allowed the detection of PrPc in both the light and the dark zones of the germinal centre (GC). The mantle zone (MZ) remained unstained. Bar $=200 \mu \mathrm{m}$.

The staining was located on the membrane extensions wrapped around lymphoid cells (Fig. 5).

Contaminant cells remained unstained except for the epithelial cells, which expressed a slight labelling (data not shown).

\subsection{Ultrastructural location of PrPc on FDC clusters}

The precise location of Pri 909 mAb labelling was confirmed on ultrathin sections after immunogold analysis by electron microscopy. A low magnification of an FDC cluster in Fig. 6 illustrates an FDC containing two nuclear sections with abundant euchromatin surrounded by a thin rim of

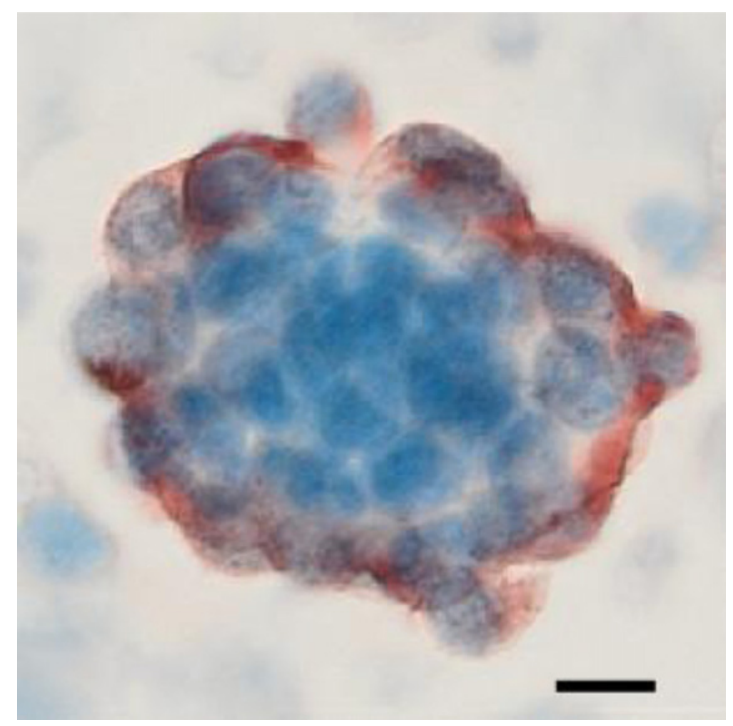

Fig. 5. Immunolabelling of an FDC cluster isolated from ovine pharyngeal tonsils with mAb: Pri 909. Counterstaining with haematoxylin. Pri 909 labelled the FDC cytoplasmic extensions surrounding several lymphocytes. Isolated lymphocytes were negative. $\mathrm{Bar}=10 \mu \mathrm{m}$.

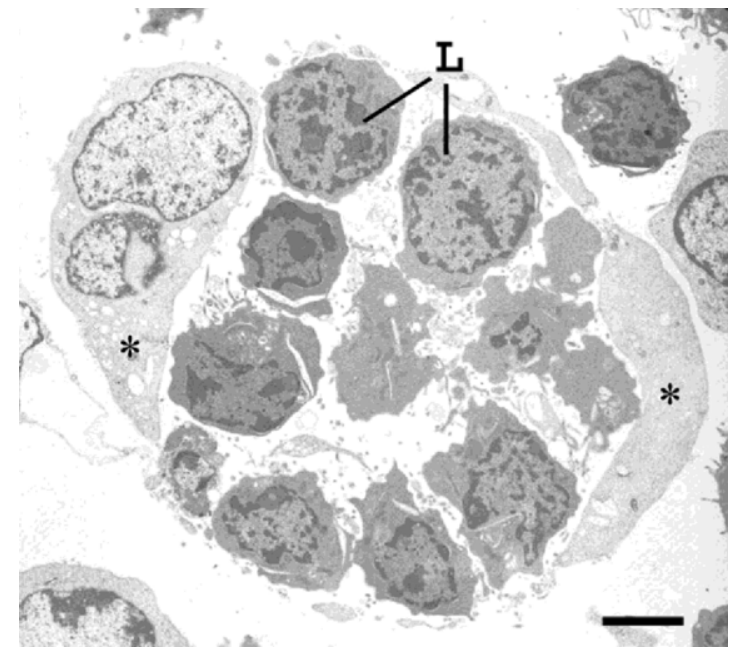

Fig. 6. Transmission electron micrograph of an FDC cluster isolated from ovine pharyngeal tonsils. The cluster appears as a round aggregate where the membrane of the FDCs $\left(^{*}\right)$ has ensheathed 12 lymphocytes (L). $\operatorname{Bar}=1.5 \mu \mathrm{m}$.

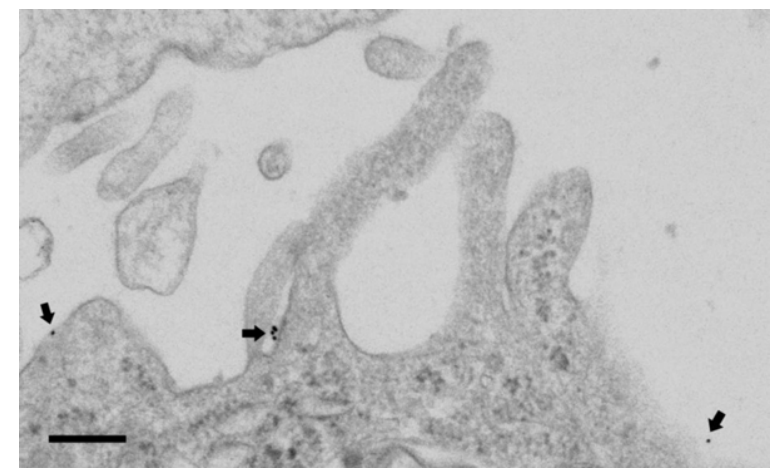

Fig. 7. Immunogold labelling with mAb: Pri 909 of an FDC cluster isolated from ovine pharyngeal tonsils. Gold particles (arrowheads) line up along the cell surface of FDC cytoplasmic extensions. Bar $=200 \mathrm{~nm}$.

heterochromatin. Cytoplasmic extensions of the FDC were shown to have engulfed some lymphocytes.

At higher magnification (Fig. 7), gold particles were localised on the extensions of the FDC cytoplasmic membrane. Macrophages and lymphocytes did not bear any gold particles. No signal occurred in the absence of Pri 909 or when it was replaced by isotype control antibody.

\section{Discussion}

It is generally accepted that in natural scrapie, sheep become infected by the pathogen protein early in life and that the route of infection is likely to be oral in the majority of cases. Dissemination of prions into the environment can occur from several types of biological material, e.g. infectious placenta, amniotic fluid, and sheep saliva. Moreover, infectivity persists in contaminated clay components of soil and aqueous soil extracts for over 29 months, leading to disease transmission by feeding or drinking (Johnson et al., 2006). 
Although the alimentary tract has been suggested as the most likely portal of entry in natural scrapie, other potential routes such as dermal scarification and the conjunctiva are thought to be effective experimentally (Hamir et al., 2008). A growing amount of data indicates that the respiratory system is involved in the pathogenesis of human and animal diseases. Sheep and hamsters inoculated with scrapie intra-nasally have been showed to develop TSE. Nasal passages in experimental models may be even more effective than the oral route in transmitting prion disease (Kincaid and Bartz, 2007). This new route of infection has long been underestimated and consequently exposure via the respiratory system merits the consideration of prion disease transmission and biosafety. In these previous studies, nasal associated lymph tissues (NALT) were found to be the earliest site of PrPd accumulation. PrPd was shown to be essentially confined to the germinal centre of some follicles in the pharyngeal tonsil, making this lymph organ a possible route for the scrapie agent dissemination.

This study describes for the first time the broad cell populations in the lymphoid compartment of pharyngeal tonsils and more specifically inside the lymphoid follicles where the scrapie agent accumulates during the period of latency. Most of the follicles were shown to have a well developed germinal centre occupied by B lymphocytes and some $T$ cells and were surrounded by a mantle zone facing the respiratory epithelium. The interfollicular and parafollicular areas essentially contained $\mathrm{T}$ lymphocytes.

We focused our attention particularly on the localisation of follicular dendritic cells (FDCs), key cells for the accumulation of prions within the lymphoreticular system in TSE diseases (Mabbott and Bruce, 2001). The ability to recognise ovine FDCs is debated. Although some authors have successfully used CNA.42, an anti-human FDC monoclonal antibody developed by Raymond et al. (1997) to identify an FDC network in ovine lymph organs, others have shown that this antibody, tested on various immune samples, is unspecific and not efficient for all lymph organs (Melot et al., 2004). A study involving the labelling of sheep's spleen with CNA.42 revealed cells located at the periphery of the follicles and absolutely devoid of classical morphological FDC characteristics (Lezmi et al., 2001). In contrast with results previously obtained by Andreoletti et al. (2000), the results of the present study showed that, when tested on both palatine and pharyngeal tonsils, CNA.42 staining was exclusively detected in the germinal centre of the pharyngeal tonsils. The divergences between the observations of these two studies could be explained by the use of different clones of CNA.42. Moreover, in our study, the labellings were carried out on cryo instead of paraffin sections. Labelling on cryosections did not need an antigen retrieval procedure that could modify the CAN.42 immunoreactivity. In view of these results, FDC-B1 mAb seems to be a specific and sensitive antibody for identifying FDCs in situ on ovine pharyngeal tonsils.

The aim of this study was to analyse the potent implication of pharyngeal follicular dendritic cells in the accumulation of the scrapie agent. Knowing that efficient lymphoreticular prion propagation requires PrPc expression in stromal and haematopoietic cells (Kaeser et al., 2001), we analysed the expression of PrPc by pharyngeal ovine FDCs. In situ, a positive staining with the Pri $909 \mathrm{mAb}$ was observed in the light but also the dark zone of the germinal centre.

PrPc labelling in the dark zone could be due to the presence of (i) immature FDCs with poorly developed cytoplasmic extensions or (ii) other immune cells. In fact, cellular prion protein is also expressed by $\mathrm{B}$ and $\mathrm{T}$ cells, platelets, erythrocytes, monocytes and dendritic cells with significant differences across species and in terms of the state of maturation of the cells (Aguzzi and Heikenwalder, 2005; Nuvolone et al., 2009). Recently, an ultrastructural analysis in situ with an immunogold labelling of the pathogen protein showed the presence of PrPd on both the FDC cytoplasmic extensions and the B lymphocyte membranes (McGovern and Jeffrey, 2007). Nevertheless, B lymphocytes are unlikely to represent a major site for prion replication (Montrasio et al., 2001). Their involvement in TSE pathogenesis is believed to be indirect, such as supporting the development and maturation of FDCs by the expression of lymphotoxin alpha and tumour necrosis factor alpha (Allen and Cyster, 2008).

In our opinion, the intimate interconnections of FDCs and the plasma membrane of B cells in situ cannot allow the precise localisation of cellular prion protein. It would thus be inappropriate to occult the natural expression of PrPc by B lymphocytes and the possible conversion of the host encoded protein by contact with the pathogen protein.

In this study, by testing various enzyme cocktails, we obtained FDC-cluster-enriched cell suspensions with wellpreserved morphology. Pharyngeal ovine FDCs were found to resemble those found in human (Velinova et al., 2001) and bovine tonsils (Thielen et al., 2001b) with fine villous extensions. As previously described by other studies (Caughey et al., 1988; Li et al., 2001; Thielen et al., 2001a), enzymatic digestion may alter phenotypic features. We found that the presence of DNase and dispase enhanced the digestion of the connective tissues but that PrPc expression by FDC clusters was no longer detected. Enzyme solution cleaves PrPc within a site located before the epitope which is recognised by Pri $909 \mathrm{mAb}$. After $15 \mathrm{~h}$ of culture, we found that freshly isolated FDC clusters re-expressed PrPc. After immunogold staining with Pri $909 \mathrm{mAb}$, gold particles were localised on cytoplamic extensions. The level of expression was determined by the number of gold particles depending on the depth of the section and on the diameter of the cluster.

The number of gold particles was low but was in agreement with results obtained by Thielen in the same conditions on bovine tonsillar FDCs (Thielen et al., 2001b).

\section{Conclusion}

Our results suggest that in the case of intranasal sheep contamination, the upper respiratory tract, specifically the pharyngeal tonsil, may serve as an entry point for prion protein in scrapie infected environments. The lymphoreticular system and more specifically PrPc expressing follicular dendritic cells could serve as a prion "reservoir" during the latency phase, thus playing a key role during the lymphoinvasion. Future studies will need to verify the real potential of FDCs to retain PrPd. Studies will also need to evalu- 
ate the mechanisms of propagation of the disease-causing agent from these cells, resident in the lymphoid follicles towards the central nervous system, the target organ for fatal lesions.

\section{Acknowledgements}

We acknowledge the technical assistance of Drs. C. Thill and P. Hubert. We thank Professor E. Heinen from the Human Histology Unit of The Faculty of Medicine of the University of Liege who kindly provided the FDC-B1 mAb.

\section{References}

Aguzzi, A., Heikenwalder, M., 2005. Prions, cytokines, and chemokines: a meeting in lymphoid organs. Immunity 22, 145-154.

Allen, C.D., Cyster, J.G., 2008. Follicular dendritic cell networks of primary follicles and germinal centers: phenotype and function. Semin. Immunol. 20, 14-25.

Andreoletti, O., Berthon, P., Marc, D., Sarradin, P., Grosclaude, J., van Keulen, L., Schelcher, F., Elsen, J.M., Lantier, F., 2000. Early accumulation of $\operatorname{PrP}(\mathrm{Sc})$ in gut-associated lymphoid and nervous tissues of susceptible sheep from a Romanov flock with natural scrapie. J. Gen. Virol. 81, 3115-3126.

Barone, R., 1997. Pharynx et Oesophage. In: Barone, R. (Ed.), Anatomie Comparée des Mammifères Domestiques, Troisième Tome: Splanchnologie. Editions Vigot, Paris, pp. 249-290.

Brown, K.L., Stewart, K., Ritchie, D.L., Mabbott, N.A., Williams, A., Fraser, H., Morrison, W.I., Bruce, M.E., 1999. Scrapie replication in lymphoid tissues depends on prion protein-expressing follicular dendritic cells. Nat. Med. 5, 1308-1312.

Casteleyn, C., Cornelissen, M., Simoens, P., Van den Broeck, W., 2010. Ultramicroscopic examination of the ovine tonsillar epithelia. Anat. Rec. (Hoboken) 293, 879-889.

Casteleyn, C., Cornillie, P., Simoens, P., Van Den Broeck, W., 2008. Stereological assessment of the epithelial surface area of the ovine palatine and pharyngeal tonsils. Anat. Histol. Embryol. 37, 366-368.

Casteleyn, C., Van den Broeck, W., Simoens, P., 2007. Histological characteristics and stereological volume assessment of the ovine tonsils. Vet. Immunol. Immunopathol. 120, 124-135.

Caughey, B., Race, R.E., Vogel, M., Buchmeier, M.J., Chesebro, B., 1988. In vitro expression in eukaryotic cells of a prion protein gene cloned from scrapie-infected mouse brain. Proc. Natl. Acad. Sci. U.S.A. 85 4657-4661.

Cocquyt, G., Baten, T., Simoens, P., Van Den Broeck, W., 2005. Anatomical localisation and histology of the ovine tonsils. Vet. Immunol. Immunopathol. 107, 79-86.

Gabriel, A.C.G., van den Broeck, W., 2003. Aspects anatomique et histologique des tonsilles du mouton. Ann. Med. Vet. 147, 251-258.

Hamir, A.N., Kunkle, R.A., Richt, J.A., Miller, J.M., Greenlee, J.J., 2008. Experimental transmission of US scrapie agent by nasal, peritoneal, and conjunctival routes to genetically susceptible sheep. Vet. Pathol. 45, 7-11.

Heppner, F.L., Christ, A.D., Klein, M.A., Prinz, M., Fried, M., Kraehenbuhl, J.P., Aguzzi, A., 2001. Transepithelial prion transport by M cells. Nat. Med. 7, 976-977.

Horsington, J., Zhang, Z., 2007. Analysis of foot-and-mouth disease virus replication using strand-specific quantitative RT-PCR. J. Virol. Methods $144,149-155$.

Jeffrey, M., McGovern, G., Goodsir, C.M., Brown, K.L., Bruce, M.E., 2000. Sites of prion protein accumulation in scrapie-infected mouse spleen revealed by immuno-electron microscopy. J. Pathol. 191, 323-332.

Jeffrey, M., Martin, S., Thomson, J.R., Dingwall, W.S., Begara-McGorum, I., Gonzalez, L., 2001. Onset and distribution of tissue prp accumulation in scrapie-affected suffolk sheep as demonstrated by sequential necropsies and tonsillar biopsies. J. Comp. Pathol. 125, 48-57.

Johnson, C.J., Phillips, K.E., Schramm, P.T., McKenzie, D., Aiken, J.M., Pedersen, J.A., 2006. Prions adhere to soil minerals and remain infectious. PLoS Pathog. 2, e32.

Johnson, G.D., Hardie, D.L., Ling, N.R., Maclennan, I.C., 1986. Human follicular dendritic cells (FDC): a study with monoclonal antibodies (MoAb). Clin. Exp. Immunol. 64, 205-213.
Kaeser, P.S., Klein, M.A., Schwarz, P., Aguzzi, A., 2001. Efficient lymphoreticular prion propagation requires $\operatorname{PrP}(\mathrm{c})$ in stromal and hematopoietic cells. J. Virol. 75, 7097-7106.

Kincaid, A.E., Bartz, J.C., 2007. The nasal cavity is a route for prion infection in hamsters. J. Virol. 81, 4482-4491.

Kitching, R.P., Hughes, G.J., 2002. Clinical variation in foot and mouth disease: sheep and goats. Rev. Sci. Tech. 21, 505-512.

Kosco, M.H., Pflugfelder, E., Gray, D., 1992. Follicular dendritic celldependent adhesion and proliferation of B cells in vitro. J. Immunol. 148, 2331-2339.

Lezmi, S., Bencsik, A., Baron, T., 2001. CNA42 monoclonal antibody identifies FDC as PrPsc accumulating cells in the spleen of scrapie affected sheep. Vet. Immunol. Immunopathol. 82, 1-8.

Li, R., Liu, D., Zanusso, G., Liu, T., Fayen, J.D., Huang, J.H., Petersen, R.B., Gambetti, P., Sy, M.S., 2001. The expression and potential function of cellular prion protein in human lymphocytes. Cell. Immunol. 207 49-58.

Mabbott, N.A., Bruce, M.E., 2001. The immunobiology of TSE diseases. J. Gen. Virol. 82, 2307-2318.

Mabbott, N.A., Mackay, F., Minns, F., Bruce, M.E., 2000. Temporary inactivation of follicular dendritic cells delays neuroinvasion of scrapie. Nat. Med. 6, 719-720.

McBride, P.A., Eikelenboom, P., Kraal, G., Fraser, H., Bruce, M.E., 1992. PrP protein is associated with follicular dendritic cells of spleens and lymph nodes in uninfected and scrapie-infected mice. J. Pathol. 168, 413-418.

McGovern, G., Jeffrey, M., 2007. Scrapie-specific pathology of sheep lymphoid tissues. PLoS One 2, e1304.

Melot, F., Defaweux, V., Jolois, O., Collard, A., Robert, B., Heinen, E., Antoine, N., 2004. FDC-B1: a new monoclonal antibody directed against bovine follicular dendritic cells. Vet. Immunol. Immunopathol. 97 1-9.

Montrasio, F., Frigg, R., Glatzel, M., Klein, M.A., Mackay, F., Aguzzi, A., Weissmann, C., 2000. Impaired prion replication in spleens of mice lacking functional follicular dendritic cells. Science 288, 1257-1259.

Montrasio, F., Cozzio, A., Flechsig, E., Rossi, D., Klein, M.A., Rulicke, T., Raeber, A.J., Vosshenrich, C.A., Proft, J., Aguzzi, A., Weissmann, C., 2001 B lymphocyte-restricted expression of prion protein does not enable prion replication in prion protein knockout mice. Proc. Natl. Acad. Sci. U.S.A. 98, 4034-4037.

Naiem, M., Gerdes, J., Abdulaziz, Z., Stein, H., Mason, D.Y., 1983. Production of a monoclonal antibody reactive with human dendritic reticulum cells and its use in the immunohistological analysis of lymphoid tissue. J. Clin. Pathol. 36, 167-175.

Nuvolone, M., Aguzzi, A., Heikenwalder, M., 2009. Cells and prions: a license to replicate. FEBS Lett. 583, 2674-2684.

Ogra, P.L., 2000. Mucosal immune response in the ear, nose and throat. Pediatr. Infect. Dis. J. 19, S4-8.

Perry, M., Whyte, A., 1998. Immunology of the tonsils. Immunol. Today $19,414-421$

Raymond, I., Al Saati, T., Tkaczuk, J., Chittal, S., Delsol, G., 1997. CNA.42, a new monoclonal antibody directed against a fixative-resistant antigen of follicular dendritic reticulum cells. Am. J. Pathol. 151, 1577-1585.

Stanley, A.C., Huntley, J.F., Jeffrey, M., Buxton, D., 2001. Characterization of ovine nasal-associated lymphoid tissue and identification of $\mathrm{M}$ cells in the overlying follicle-associated epithelium. J. Comp. Pathol. 125, 262-270.

Thielen, C., Antoine, N., Melot, F., Cesbron, J.Y., Heinen, E., Tsunoda, R., 2001a. Human FDC express PrPc in vivo and in vitro. Dev. Immunol. 8, 259-266.

Thielen, C., Melot, F., Jolois, O., Leclercq, F., Tsunoda, R., Frobert, Y., Heinen, E., Antoine, N., 2001b. Isolation of bovine follicular dendritic cells allows the demonstration of a particular cellular prion protein. Cell Tissue Res. 306, 49-55.

Thuring, C.M., Crowe, M.A., McAllister, H., Earley, B., Roche, J.F., Sweeney, T., 2002. Evaluation of peripheral lymphoreticular biopsy techniques and their clinical side effects in sheep. Vet. Rec. 150, 97-102.

Tsunoda, R., Nakayama, M., Onozaki, K., Heinen, E., Cormann, N., KinetDenoel, C., Kojima, M., 1990. Isolation and long-term cultivation of human tonsil follicular dendritic cells. Virchows Arch. B Cell. Pathol. Incl. Mol. Pathol. 59, 95-105.

Velinova, M., Thielen, C., Melot, F., Donga, J., Eicher, S., Heinen, E., Antoine, N., 2001. New histochemical and ultrastructural observations on normal bovine tonsils. Vet. Rec. 149, 613-617. 